Research Article

\title{
Detection of Adulterated Honey by Fluorescence Excitation-Emission Matrices
}

\author{
Tatjana Dramićanin (D), Lea Lenhardt Acković, Ivana Zeković (D), \\ and Miroslav D. Dramićanin (ID
}

Vinča Institute of Nuclear Sciences, University of Belgrade, Belgrade 11001, Serbia

Correspondence should be addressed to Tatjana Dramićanin; tatjana@vinca.rs and Miroslav D. Dramićanin; dramican@vinca.rs

Received 22 February 2018; Revised 26 April 2018; Accepted 24 May 2018; Published 2 July 2018

Academic Editor: Feride Severcan

Copyright ( $\odot 2018$ Tatjana Dramićanin et al. This is an open access article distributed under the Creative Commons Attribution License, which permits unrestricted use, distribution, and reproduction in any medium, provided the original work is properly cited.

\begin{abstract}
Honey is a frequent target of adulteration through inappropriate production practices and origin mislabelling. Current methods for the detection of adulterated honey are time and labor consuming, require highly skilled personnel, and lengthy sample preparation. Fluorescence spectroscopy overcomes such drawbacks, as it is fast and noncontact and requires minimal sample preparation. In this paper, the application of fluorescence spectroscopy coupled with statistical tools for the detection of adulterated honey is demonstrated. For this purpose, fluorescence excitation-emission matrices were measured for 99 samples of different types of natural honey and 15 adulterated honey samples (in 3 technical replicas for each sample). Statistical $t$-test showed that significant differences between fluorescence of natural and adulterated honey samples exist in 5 spectral regions: (1) excitation: $240-265 \mathrm{~nm}$, emission: $370-495 \mathrm{~nm}$; (2) excitation: $280-320 \mathrm{~nm}$, emission: 390-470 nm; (3) excitation: $260-$ $285 \mathrm{~nm}$, emission: $320-370 \mathrm{~nm}$; (4) excitation: 310-360 nm, emission: 370-470 nm; and (5) excitation: 375-435 nm, emission: $440-520 \mathrm{~nm}$, in which majority of fluorescence comes from the aromatic amino acids, phenolic compounds, and fluorescent Maillard reaction products. Principal component analysis confirmed these findings and showed that $90 \%$ of variance in fluorescence is accumulated in the first two principal components, which can be used for the discrimination of fake honey samples. The classification of honey from fluorescence data is demonstrated with a linear discriminant analysis (LDA). When subjected to LDA, total fluorescence intensities of selected spectral regions provided classification of honey (natural or adulterated) with $100 \%$ accuracy. In addition, it is demonstrated that intensities of honey emissions in each of these spectral regions may serve as criteria for the discrimination between natural and fake honey.
\end{abstract}

\section{Introduction}

Honey is a pure natural food produced by bees from the nectar of flowers. Its main components are different types of carbohydrates, water, and some minor constituents, such as pollen grains, proteins, amino acids, lipids, alkaloids, enzymes, and flavoring components. The composition and concentrations of minor constituents are unique characteristics of honey, and some of them can be used to differentiate honey samples by their geographical and botanical origins, as well as to define their quality and authenticity [1].

According to European Union standards [2], honey is a pure product, in which no components can be added or removed from. According to the botanical origin, honey can be categorized into two groups: honeydew and nectar honey types. Nectar honey in turn is divided into polyfloral and monofloral honey. Polyfloral honey contains nectar from different plant species, while monofloral is from single plant species with more than $45 \%$ of the total pollen in honey [3]. However, a minimum percentage of pollen in monofloral honey may be different for various types of honey. For example, the Sunflower pollen should not be less than $45 \%$ of the total pollen, but for acacia and linden, it should not be less than $30 \%$ in honey [4]. Eucalyptus honey and chestnut honey, having overrepresented pollen grains, can show a pollen frequency of $70 \%$ to $90 \%$ [5]. 
According to the Serbian regulations, acacia honey, linden honey, and sunflower honey are defined as monofloral when pollen concentration is over $20 \%, 25 \%$, and $40 \%$, respectively.

As a relatively expensive food product, honey is a frequent target of adulteration through inappropriate production practices and its origin mislabelling [6]. This presents a serious issue on markets and violates consumer rights. Much effort, thus, is nowadays directed for the development of characterization methods for honey to fight this problem. For example, to prove the geographical and botanical origin of honey, the microscopic analysis of pollen grains [7-9] is a common method. However, it is time-consuming method and requires work of an experienced operator. Other methods, according to European Union legislation [2], include physicochemical analysis [10-12], proton nuclear magnetic resonance $\left({ }^{1} \mathrm{H}\right.$ NMR) imaging [13], sensory analysis [14], chromatography [15-17], and electric-tongue analysis [18, 19]. Unfortunately, these methods are time and labor consuming, require highly skilled personnel, and lengthy sample preparation.

Optical spectroscopy methods are less demanding in this respect, and many of them are successfully applied in food analyses [20, 21]. Near infrared (NIR) spectroscopy in combination with chemometric methods was used for the quantitative and qualitative detection of beet syrup adulteration of honey [22], adulteration of honey with mixtures of fructose and glucose [23], and adulteration of honey with HFCS (highfructose corn syrup) [24]. The application of mid-FTIR spectroscopy coupled with the SVM (support vector machine) algorithm provided the determination of the botanical origin of Serbian unifloral honey [25]. Fluorescence spectroscopy offers advantages over classic methods of food analysis, such as minimal sample preparation, high sensitivity and specificity of classification [26], and rapid and relatively simple use of instrumentation. This technique is suitable for the analysis and authentication of food products such as milk [27], cheese [28], cereal flours [29], and wine [30]. Geographical and botanical origin of honey samples have been authenticated by fluorescence spectroscopy [31]. Recently, parallel factor analysis (PARAFAC) has been used to fully describe fluorescence of honey [32] and cereal flour [33]. Since there is no quantitative fluorescence marker for the detection of fake honey, fluorescence of honey intrinsic fluorophores must be utilized for the analysis.

Here, we aimed at exploring differences in fluorescence between natural honey and adulterated honey which arise due to dissimilar composition of fluorescence species that are present in them. For this purpose, we measured fluorescence excitation-emission matrices of 114 samples of natural and fake honey samples (in three technical replicas) aiming at developing the fluorescence-based technique for the fast and nondestructive detection of honey adulteration. Principal component and linear discriminant analysis of characteristic honey emission features were utilized to describe observed differences and to build and test the classification model.

\section{Materials and Methods}

2.1. Samples. In this research, a total of 114 samples, 99 natural honey samples (45 acacias, 11 lindens, 14 sunflowers, and 29 meadow mixes) and 15 fake honey samples, were obtained from the Association of the Beekeeping Organizations of Serbia (SPOS, www.spos.info). Fake honey samples were manufactured during winter feeding of bee colonies with a sucrose solution, which was later converted into artificial honey by bees. Honey samples were stowed in the original packages at $20-22^{\circ} \mathrm{C}$ until analysis.

\subsection{Measurements of Fluorescence Excitation-Emission} Matrices. Room temperature fluorescence excitationemission matrices (EEMs) were obtained by a Perkin Elmer Fluorescence Spectrophotometer LS45 in a front face measurement configuration. The instrument was equipped with a Xe lamp for excitations and a R928 PMT for the detection of emission radiation. EEMs were recorded over the $270-640 \mathrm{~nm}$ emission range (at $0.5 \mathrm{~nm}$ intervals) and 240-500 $\mathrm{nm}$ excitation range (with a $5 \mathrm{~nm}$ step). Emission intensities were automatically normalized to the excitation intensity by the instrument. Honey samples were liquefied at $40^{\circ} \mathrm{C}$ and pipetted into $3 \mathrm{~mL}$ quartz cuvettes before measurements. Contributions to measured signal intensity from the first and second order Rayleigh scattering were removed and replaced with interpolated values. The use of interpolated values to remove scattering contribution has been shown to provide better and more meaningful results when dealing with EEMs compared to the data deletion [34].

2.3. Data Analysis. Data analyses comprised the calculation of spectral domain volumes below EEM intensity surfaces, testing of the statistical significance of differences observed between spectral characteristics of natural and fake honey samples by a $t$-test, investigating differences by principal component analysis (PCA) and the classification of samples using a linear discriminant analysis (LDA) of EEM data. Analyses were performed using the $\mathrm{R}$ software package (R Foundation for Statistical Computing, Vienna, Austria).

Spectral domain volumes (spectral domain being represented by maximal and minimal values of excitation and emission wavelengths, $\lambda$ ) are numerically calculated from the measured emission intensity $I\left(\lambda_{\mathrm{exc}}, \lambda_{\mathrm{em}}\right)$ using the following formula [35]:

$$
\begin{array}{r}
\int_{\lambda_{\mathrm{exc}}^{\min }}^{\lambda_{\mathrm{exc}}^{\max }} \int_{\lambda_{\mathrm{em}}^{\min }}^{\lambda_{\mathrm{mex}}^{\max }} I\left(\lambda_{\mathrm{exc}}, \lambda_{\mathrm{em}}\right) d \lambda_{\mathrm{em}} d \lambda_{\mathrm{exc}} \\
=\Delta \lambda_{\mathrm{em}} \Delta \lambda_{\mathrm{exc}} \sum_{j=1}^{M} \sum_{i=1}^{N} I\left(\lambda_{\mathrm{exc}}^{j}, \lambda_{\mathrm{em}}^{i}\right),
\end{array}
$$

where $\quad \lambda_{\text {exc }}^{j}=\lambda_{\text {exc }}^{\min }+j \Delta \lambda_{\text {exc }}, \lambda_{\text {em }}^{i}=\lambda_{\text {em }}^{\text {min }}+i \Delta \lambda_{\text {em }}, \Delta \lambda_{\text {exc }}=$ $\left(\lambda_{\text {exc }}^{\max }-\lambda_{\text {exc }}^{\min }\right) / M, \Delta \lambda_{\text {em }}=\left(\lambda_{\text {em }}^{\max }-\lambda_{\text {em }}^{\min }\right) / M$, and $M$ and $N$ are the numbers of measurement intervals for excitation and emission, respectively.

Principal component analysis (PCA) is a method used for reducing data dimensionality and identifying differences between analysed samples as well as investigating and visualizing variations found in a data set [36]. To apply PCA, three-way data array must be unfolded into two-dimensional 


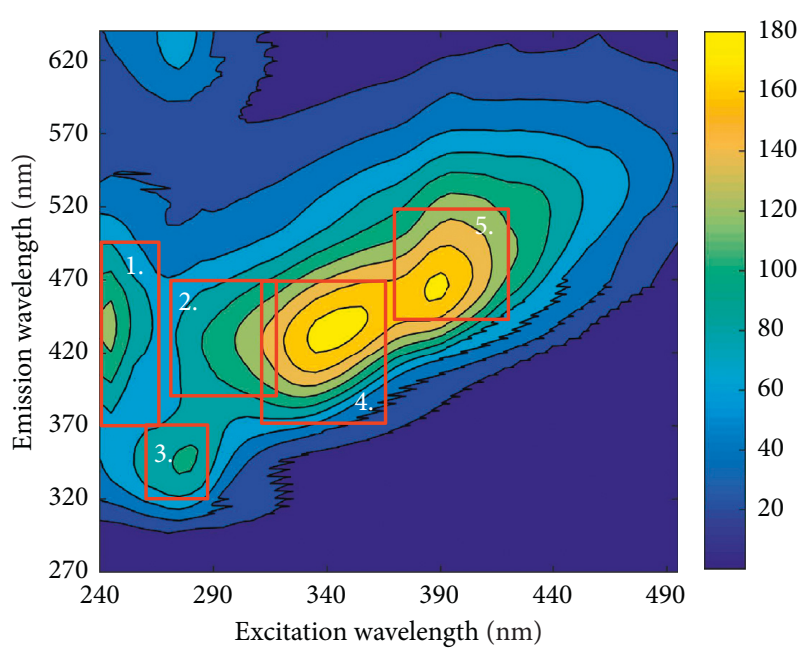

(a)

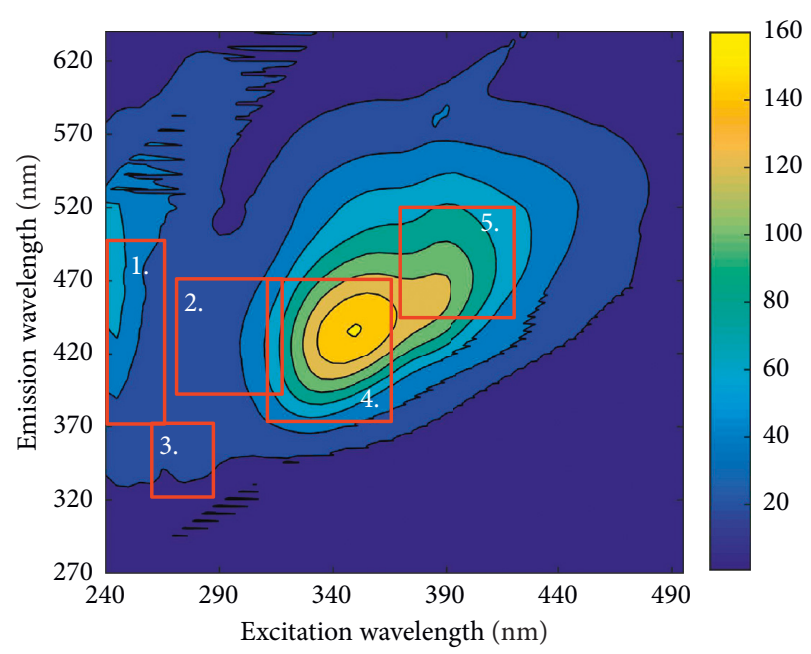

(b)

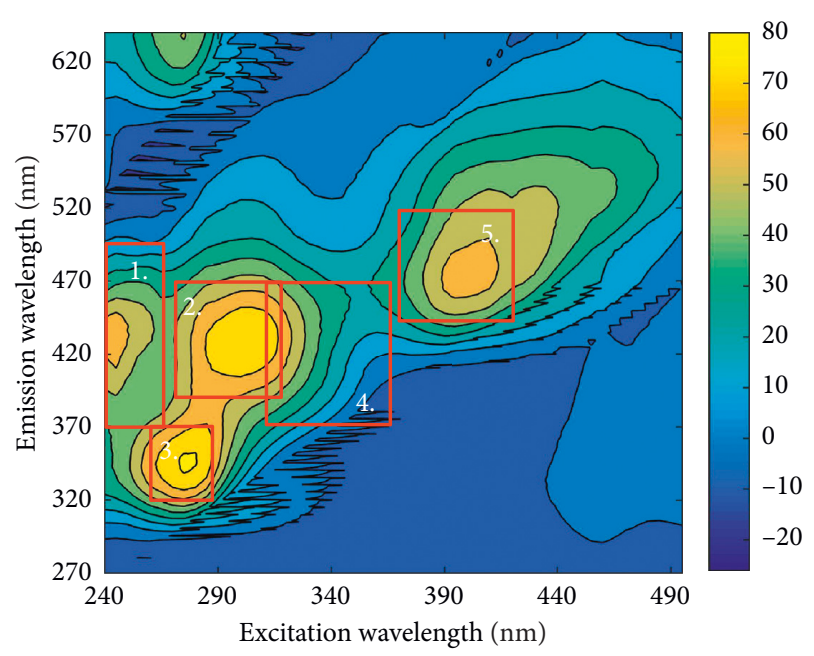

(c)

FIgURE 1: Fluorescence excitation-emission matrices of (a) naturaland (b) fake honey and (c) their difference spectrum. The discussedspectral regions are marked with a full line
TABLE 1: Spectral regions showing characteristic fluorescence of honey fluorophores.

\begin{tabular}{lccc}
\hline Spectral domain & $\lambda_{\mathrm{ex}}(\mathrm{nm})$ & $\lambda_{\mathrm{em}}(\mathrm{nm})$ & Fluorophore \\
\hline 1st & $240-265$ & $370-495$ & Phenolic compounds \\
2nd & $280-320$ & $390-470$ & Phenolic compounds \\
3rd & $260-285$ & $320-370$ & Aromatic amino acids \\
4th & $310-360$ & $370-470$ & $\begin{array}{c}\text { Phenolic compounds } \\
\text { 5th }\end{array}$ \\
\hline
\end{tabular}

TABLE 2: Statistical analysis mean values, standard deviation: SD, and statistical significance of difference between means: $p$ of five spectral domain volumes (marked on Figure 1) in EEMs of 99 natural and 15 fake honey.

\begin{tabular}{llllc}
\hline Spectral domain & Honey & Mean* & SD $^{*}$ & $p^{* *}$ \\
\hline \multirow{2}{*}{ st } & Natural & $1.38 \times 10^{5}$ & 3399 & \multirow{2}{*}{$4.90 \times 10^{-13}$} \\
& Fake & $6.13 \times 10^{4}$ & 8688 & \\
2nd & Natural & $9.42 \times 10^{4}$ & 2580 & $2.03 \times 10^{-11}$ \\
& Fake & $4.14 \times 10^{4}$ & 6597 & \\
3rd & Natural & $5.70 \times 10^{4}$ & 1895 & $7.97 \times 10^{-12}$ \\
& Fake & $1.73 \times 10^{4}$ & 4844 & \\
4th & Natural & $3.37 \times 10^{5}$ & 6844 & $5.44 \times 10^{-13}$ \\
& Fake & $1.83 \times 10^{5}$ & 17494 & \\
5th & Natural & $3.08 \times 10^{5}$ & 5191 & \multirow{2}{*}{$3.12 \times 10^{-21}$} \\
& Fake & $1.40 \times 10^{5}$ & 13268 & \\
\hline
\end{tabular}

${ }^{*}$ Values are in counts $\times \mathrm{nm}^{2}$. ${ }^{* *}$ Decision on statistical significance is made in a traditional way based on a probability value for the null hypothesis. $p$ : $>0.05$, not significant; 0.05 to 0.01 , significant; 0.01 to 0.001 , very significant; $<0.001$, extremely significant.

(2D) matrix. This is achieved by unfolding initial data array (114 samples $\times 741$ emissions $\times 53$ excitations) into a $2 \mathrm{D}$ matrix (114 samples $\times 39273$ parameters (emissions $\times$ excitations)). After the analysis, the calculated loadings can be refolded back into a three-way data array. PCA was applied on unfolded EEM spectra to explore differences between natural and fake honey and to determine which parts of EEM spectrum contribute the most to those differences. This was carried out by investigating calculated PCA scores and loadings.

Linear discriminant analysis (LDA) is a linear classification method with a goal to find one or more linear functions of the input variables which, then, can be used for the sample classification. Fisher's algorithm [37] is used for the building LDA classification model utilizing the spectral domain volumes as input data. K-fold cross-validation was used to calculate classification error. Samples were divided three times in such way that two thirds of samples were used for the training of the classification model, while the one third was used for model testing. From three tastings, the mean classification error was derived.

\section{Results and Discussion}

Figure 1 shows EEM spectra of natural and fake honey samples as well as the difference spectrum in forms of contour maps.

Intrinsic fluorophores and their specific microenvironments in honey produce a complex excitation-emission pattern which varies among samples. As presented in 


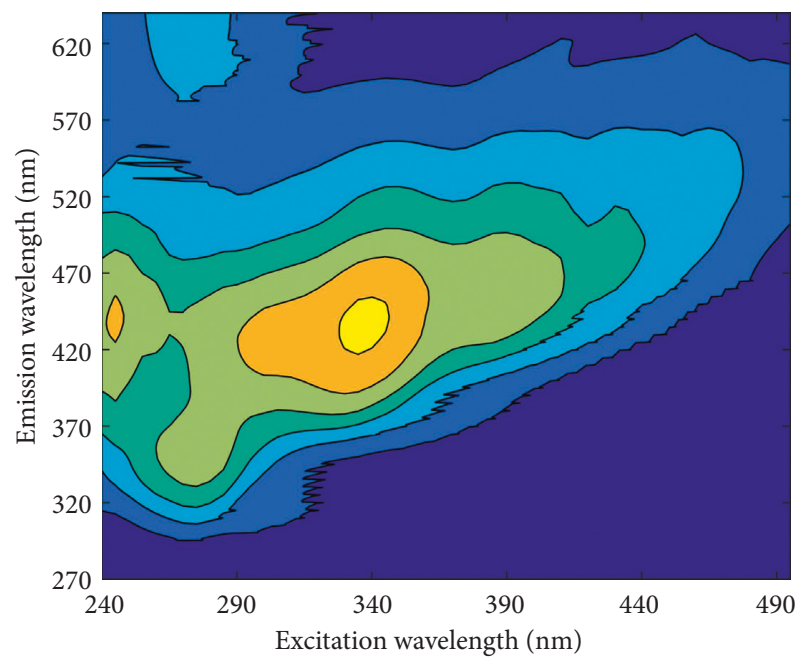

(a)

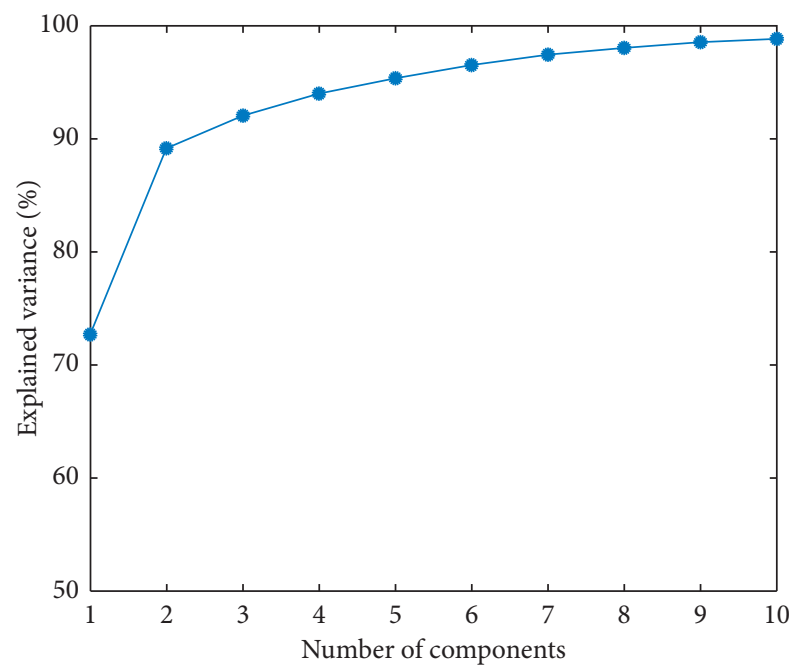

(c)

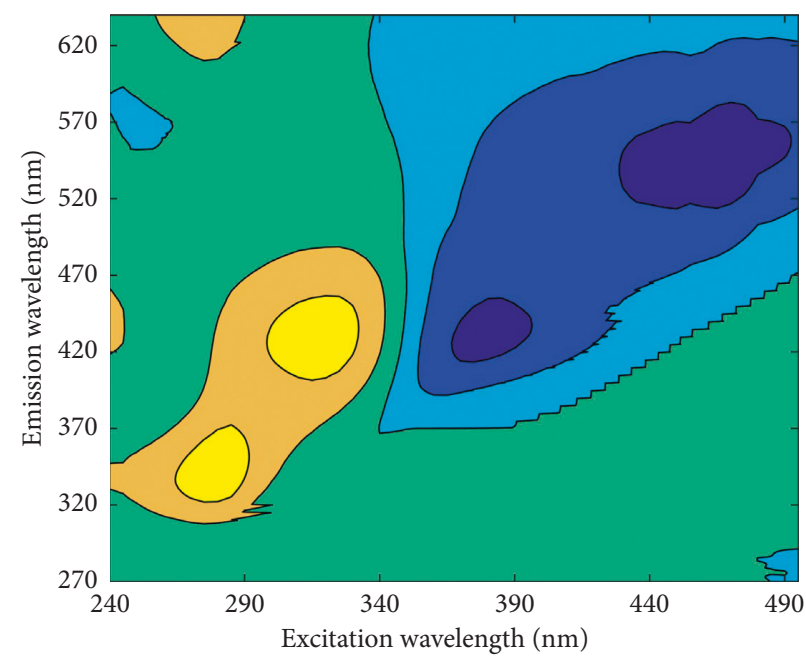

(b)

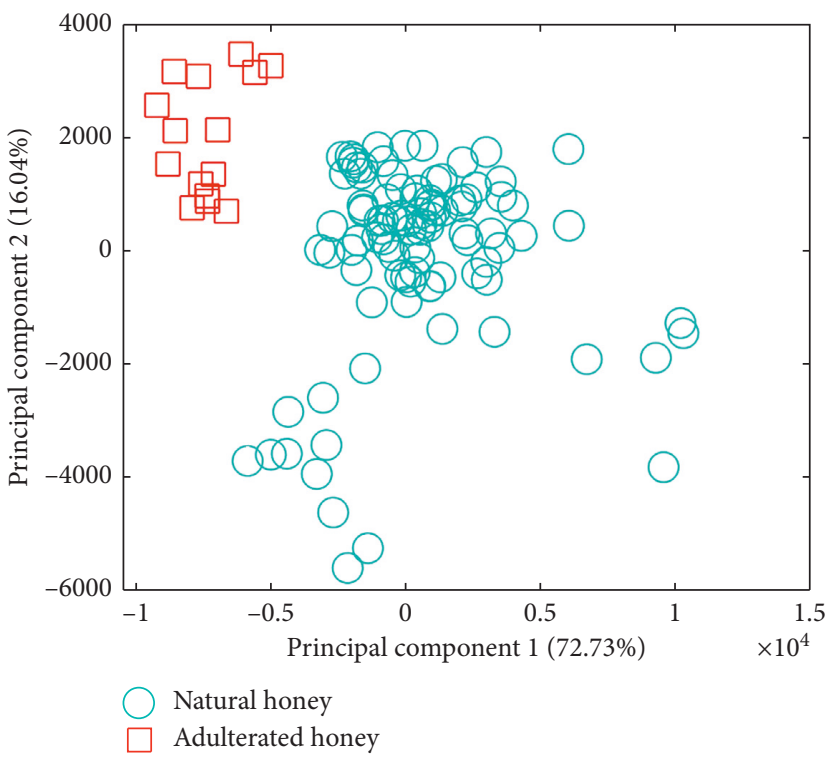

(d)

FIgUre 2: Results of PCA of unfolded honey EEM spectra: (a) loadings of the first principal component, (b) loadings of the second principal component, (c) cumulative variance plot, and (d) the PCA score plot.

Table 1, fluorescence EEMs of honey are characterized by 5 spectral regions of high emission intensities: (1) excitation: 240-265 nm, emission: 370-495 nm; (2) excitation: 280$320 \mathrm{~nm}$, emission: $390-470 \mathrm{~nm}$; (3) excitation: $260-285 \mathrm{~nm}$, emission: $320-370 \mathrm{~nm}$; (4) excitation: $310-360 \mathrm{~nm}$, emission: $370-470 \mathrm{~nm}$, and (5) excitation: $375-435 \mathrm{~nm}$, emission: $440-520 \mathrm{~nm}$ (marked on Figure 1 with a full line). These emissions come from the aromatic amino acids, phenolic compounds, and fluorescent Maillard reaction products, such as furosine and hydroxymethylfurfural [32]. One should note that hydroxymethylfurfural is an indicator for the evaluation of honey storage and heat damage and that its concentration varies between natural and adulterated honey. The total emission intensities over these spectral regions are quantified according to (1) for each sample, and differences between natural and fake honey samples are tested on the statistical significance using $t$-test (Table 2).
Differences in fluorescence of natural and fake honey samples are extremely significant in all spectral regions $(p<0.001)$. Therefore, the total fluorescence intensity in each spectral region may serve as a criterion for the detection of fake honey.

PCA was performed for the further study of differences between fluorescence responses of honey and fake honey samples; results are presented in Figure 2. Loadings of the first and second principal components are given in Figures 2(a) and 2(b) as contour plots (PCA analysis was applied to unfolded spectra; the obtained loadings were transformed into two-dimensional matrix for the presentation). These plots confirmed that variations of fluorescence between samples are largest in the selected spectral regions. Variations in the first, third, and fourth regions are described by the first principal component (Figure 2(a)), while variations in the second, third, and fifth are described by the second 
TABLE 3: LDA classification and cross-validation errors.

\begin{tabular}{lcc}
\hline & $\begin{array}{c}\text { Classification } \\
\text { error (\%) }\end{array}$ & $\begin{array}{c}\text { Cross-validation } \\
\text { error (\%) }\end{array}$ \\
\hline $\begin{array}{l}\text { Natural } \\
\text { honey }\end{array}$ & 0 & 0 \\
Fake honey & 0 & 0 \\
\hline
\end{tabular}

principal component. From the cumulative variance plot (Figure 2(c)), one can observe that the first and second principal components account for almost $90 \%$ of variations in honey EEM data. The score plot of the first and second principal components of natural and adulterated honey samples' EEMs (Figure 2(d)) clearly demonstrates the distinctive separation between two groups of samples.

The quality of fluorescence-based discrimination between natural and fake honey samples was evaluated by a linear discriminant analysis (LDA) of 5 spectral domain volumes. LDA is a method used to find one or several linear functions (linear latent variables) of the data features that can be used for separation between two or more groups $[37,38]$. For estimation of classification performance, LDA classification errors were obtained and are given in Table 3. For this study, the 3-fold split of data were used as the crossvalidation method (data set was divided differently three times, while each time two thirds of the samples were used for the classification training and one third for the model testing). Perfect classification and cross-validation ( $0 \%$ error) is achieved for the set of 114 honey samples. Therefore, as expected from the previous results, the obtained confusion and prediction matrix showed correct classification of all natural honey samples (99/99) and fake (15/15) honey samples. There were zero samples misclassified. This result was expected since all spectral domain volumes showed extremely significant differences between natural and fake honey samples. As mentioned before, standard methods used for detection of honey adulteration such as isotopic, chromatographic, or thermal analysis are often destructive, time-consuming, and usually expensive. Therefore, based on our results, one can conclude that fluorescence EEMs can be used to detect fake honey in fast and nondestructive manner and that this method has a potential for the detection of adulteration of lower percentages. This would be the subject of the future study.

\section{Conclusions}

To conclude, fluorescence excitation-emission spectroscopy can be effectively used for the nondestructive and fast detection of adulterated honey specimens. Differences in fluorescence of natural and adulterated honey samples are extremely significant in five spectral regions due to differences in concentrations and local environments of aromatic amino acids, phenolic compounds, furosine, and hydroxymethylfurfural, as is demonstrated by statistical testing and PCA. By quantifying fluorescence responses and subjecting them to the statistical classification technique, for example, LDA, it is possible to detect adulterated honey with $100 \%$ accuracy. Such accuracy suggests that fluorescence excitation-emission spectroscopy may be a promising method for the low-level adulteration of honey, which is the subject of our future work.

\section{Data Availability}

Data are available upon request to Lea Lenhardt Acković (lea.lenhardt@gmail.com).

\section{Conflicts of Interest}

The authors declare that there are no conflicts of interest regarding the publication of this paper.

\section{Acknowledgments}

The authors acknowledge the financial support of the Ministry of Education, Science and Technological Development of the Republic of Serbia (Projects 45020 and 173049).

\section{References}

[1] E. Schievano, E. Morelato, C. Facchin, and S. Mammi, "Characterization of markers of botanical origin and other compounds extracted from unifloral honeys," Journal of Agriculture and Food Chemistry, vol. 61, no. 8, pp. 1747-1755, 2013.

[2] Directive 2014/63/EU of The European Parliament and of the Council of 15 May 2014 amending Council Directive 2001/110/ EC Relating to Honey, Official Journal of the European Communites, L 164, pp. 1-5, 2014.

[3] V. M. Bryant Jr. and G. D. Jones, "The $R$ values of honey: pollen coefficients," Palynology, vol. 25, no. 1, pp. 11-28, 2001.

[4] http://honeypedia.info/monofloral-and-polyfloral-honey-varieties.

[5] J. Pires, M. L. Estevinho, X. Feás, J. Cantalapiedra, and A. Iglesias, "Pollen spectrum and physico-chemical attributes of heather (Erica sp.) honeys of north Portugal," Journal of the Science of Food and Agriculture, vol. 89, no. 11, pp. 1862-1870, 2009.

[6] S. Soares, J. S. Amaral, M. B. P. P. Oliveira, and I. Mafra, “A comprehensive review on the main honey authentication issues: production and origin," Comprehensive Reviews in Food Science and Food Safety, vol. 16, no. 5, pp. 1072-1100, 2017.

[7] J. V. Marcos, R. Nava, G. Cristóbal et al., “Automated pollen identification using microscopic imaging and texture analysis," Micron, vol. 68, pp. 36-46, 2015.

[8] L. P. Oddo, M. G. Piazza, A. G. Sabatini, and M. Accorti, "Characterisation of unifloral honeys," Apidologie, vol. 26, no. 6, pp. 453-465, 1995.

[9] W. Von der Ohe, L. P. Oddo, M. L. Piana, M. Morlot, and P. Martin, "Harmonized methods of melissopalynology," Apidologie, vol. 35, no. 1, pp. 18-25, 2004.

[10] L. P. Oddo and R. Piro, "Main European unifloral honeys: descriptive sheets," Apidologie, vol. 35, no. 1, pp. 38-81, 2004.

[11] M. G. Piazza, M. Accorti, and L. P. Oddo, "Electrical conductivity, ash, colour and specific rotatory power in Italian unifloral honeys," Apicoltura, vol. 7, pp. 51-63, 1991.

[12] R. Goodacre, B. S. Radovic, and E. Anklam, "Progress toward the rapid nondestructive assessment of the floral origin of European honey using dispersive Raman spectroscopy," Applied Spectroscopy, vol. 56, no. 4, pp. 521-527, 2002. 
[13] E. F. Boffo, L. A. Tavares, A. C. T. Tobias, M. M. C. Ferreira, and A. G. Ferreira, "Identification of components of Brazilian honey by $1 \mathrm{H}$ NMR and classification of its botanical origin by chemometric methods," LWT-Food Science Technology, vol. 49, no. 1, pp. 55-63, 2012.

[14] L. Piana, L. P. Oddo, A. Bentabol et al., "Sensory analysis applied to honey: state of art," Apidologie, vol. 35, no. 1, pp. 26-37, 2004.

[15] K. A. Aliferis, P. A. Tarantilis, P. C. Harizanis, and E. Alissandrakis, "Botanical discrimination and classification of honey samples applying gas chromatography/mass spectrometry fingerprinting of headspace volatile compounds," Food Chemistry, vol. 121, no. 3, pp. 856-862, 2010.

[16] C. B. Y. Cordella, J. S. L. T. Militao, and D. Cabrol-Bass, "A simple method for automated pretreatment of usable chromatographic profiles in pattern-recognition procedures: application to HPAEC-PAD chromatograms of honeys," Analytical and Bioanalytical Chemistry, vol. 377, no. 1, pp. 214-219, 2003.

[17] J. F. Cotte, H. Casabianca, S. Chardon, J. Lheritier, and M. F. G. Loustalot, "Chromatographic analysis of sugars applied to the characterisation of monofloral honey," Analytical and Bioanalytical Chemistry, vol. 380, no. 4, pp. 698-705, 2004.

[18] N. Major, K. Markovic, M. Krpan, G. Šarić, M. Hruškar, and N. Vahčić, "Rapid honey characterization and botanical classification by an electronic tongue," Talanta, vol. 85, no. 1 , pp. 569-574, 2011.

[19] P. A. Ulloa, R. Guerra, A. M. Cavaco, A. M. R. da Costa, A. C. Figueira, and A. F. Brigas, "Determination of the botanical origin of honey by sensor fusion of impedance e-tongue and optical spectroscopy," Computers and Electronics in Agriculture, vol. 94, pp. 1-11, 2013.

[20] D. P. Perez, M. T. Sanchez, G. Cano, and A. Garrido, “Authentication of green asparagus varieties by near-infrared reflectance spectroscopy," Journal of Food Science, vol. 66, no. 2, pp. 323-327, 2001.

[21] L. E. Rodriguez-Saona, M. M. Giusti, and M. Shotts, "Advances in infrared spectroscopy for food authenticity testing A2," in Advances in Food Authenticity Testing, G. Downey, Ed., pp. 71-116, Woodhead Publishing, Cambridge, UK, 2016.

[22] S. F. Li, R. Z. Wen, Y. Yin, Z. Zhou, and Y. Shan, "Qualitative and quantitative detection of beet syrup adulteration of honey by near-infrared spectroscopy: a feasibility study," Spectroscopy and Spectral Analysis, vol. 33, no. 10, pp. 2637-2641, 2013.

[23] X. Zhu, S. Li, Y. Shan et al., "Detection of adulterants such as sweetener materials in honey using near-infrared spectroscopy and chemometrics," Journal of Food Engineering, vol. 101, no. 1, pp. 92-97, 2010.

[24] L. Chen, X. Xue, Z. Ye et al., "Determination of Chinese honey adulterated with high-fructose corn syrup by near-infrared spectroscopy," Food Chemistry, vol. 128, no. 4, pp. 1110-1114, 2011.

[25] L. Lenhardt, I. Zeković, T. Dramićanin et al., "Authentication of the botanical origin of unifloral honey by infrared spectroscopy coupled with support vector machine algorithm," Physica Scripta, vol. T162, article 014042, 2014.

[26] G. M. Strasburg and R. D. Ludescher, "Theory and application of fluorescence spectroscopy in food research," Trends in Food Science and Technology, vol. 6, no. 3, pp. 69-75, 1995.

[27] A. A. Kulmyrzaev, D. Levieux, and E. Dufour, "Front-face fluorescence spectroscopy allows the characterization of mild heat treatments applied to milk. Relations with the denaturation of milk proteins," Journal of Agricultural and Food Chemistry, vol. 53, no. 3, pp. 502-507, 2005.

[28] R. Karoui, É. Dufour, L. Pillonel et al., "The potential of combined infrared and fluorescence spectroscopies as a method of determination of the geographic origin of Emmental cheeses," International Dairy Journal, vol. 15, no. 3, pp. 287-298, 2005.

[29] I. Zeković, L. Lenhardt, T. Dramićanin, and M. D. Dramićanin, "Classification of intact cereal flours by front-face synchronous fluorescence spectroscopy," Food Analytical Methods, vol. 5, no. 5, pp. 1205-1213, 2012.

[30] D. Airado-Rodríguez, T. Galeano-Díaz, I. Durán-Merás, and J. P. Wold, "Usefulness of fluorescence excitation-emission matrices in combination with PARAFAC, as fingerprints of red wines," Journal of Agricultural and Food Chemistry, vol. 57, no. 5, pp. 1711-1720, 2009.

[31] K. Ruoff, W. Luginbühl, R. Künzli et al., "Authentication of the botanical and geographical origin of honey by front-face fluorescence spectroscopy," Journal of Agricultural and Food Chemistry, vol. 54, no. 18, pp. 6858-6866, 2006.

[32] L. Lenhardt, R. Bro, I. Zeković, T. Dramićanin, and M. D. Dramićanin, "Fluorescence spectroscopy coupled with PARAFAC and PLS DA for characterization and classification of honey," Food Chemistry, vol. 175, pp. 284-291, 2015.

[33] L. Lenhardt, I. Zeković, T. Dramićanin et al., "Characterization of cereal flours by fluorescence spectroscopy coupled with PARAFAC," Food Chemistry, vol. 229, pp. 165-171, 2017.

[34] S. Elcoroaristizabal, R. Bro, J. A. García, and L. T. Alonso, "PARAFAC models of fluorescence data with scattering: a comparative study," Chemometrics and Intelligent Laboratory Systems, vol. 142, pp. 124-130, 2015.

[35] T. Dramićanin, M. D. Dramićanin, V. Jokanović, D. NikolićVukosavljević, and B. Dimitrijević, "Three-dimensional total synchronous luminescence spectroscopy criteria for discrimination between normal and malignant breast tissue," Photochemistry and Photobiology, vol. 81, no. 6, pp. 15541558, 2005.

[36] L. Lenhardt, I. Zeković, T. Dramićanin, M. D. Dramićanin, and R. Bro, "Determination of the botanical origin of honey by front-face synchronous fluorescence spectroscopy," $A p$ plied Spectroscopy, vol. 68, no. 5, pp. 557-563, 2014.

[37] K. Varmuza and P. Filzmoser, Introduction to Multivariate Statistical Analysis in Chemometrics, CRC Press, Boca Raton, FL, USA, 2009.

[38] I. Zeković, T. Dramićanin, L. Lenhardt, J. Bandić, and M. D. Dramićanin, "Discrimination among melanoma, nevi, and normal skin by using synchronous luminescence spectroscopy," Applied Spectroscopy, vol. 68, no. 8, pp. 823-830, 2014. 

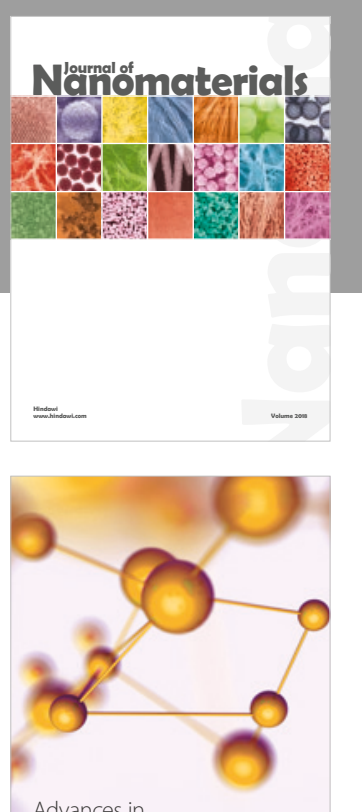

Physical Chemistry
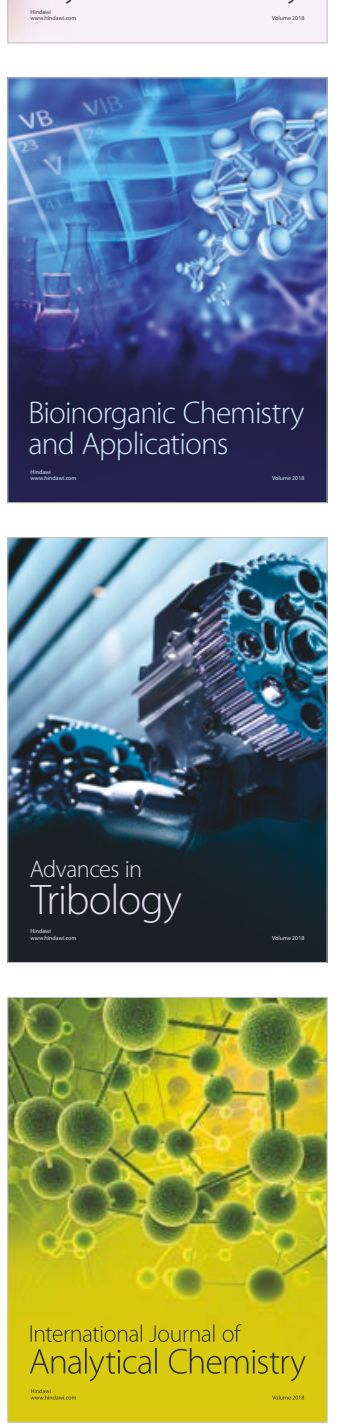

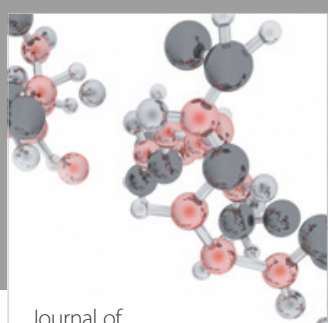

Analytical Methods

in Chemistry

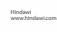

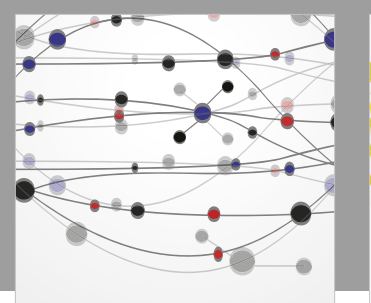

The Scientific World Journal

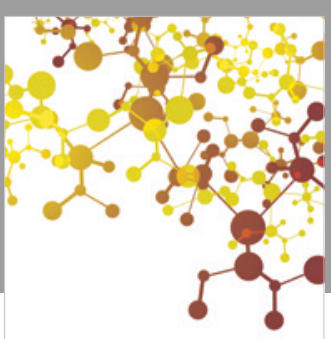

Journal of

Applied Chemistry
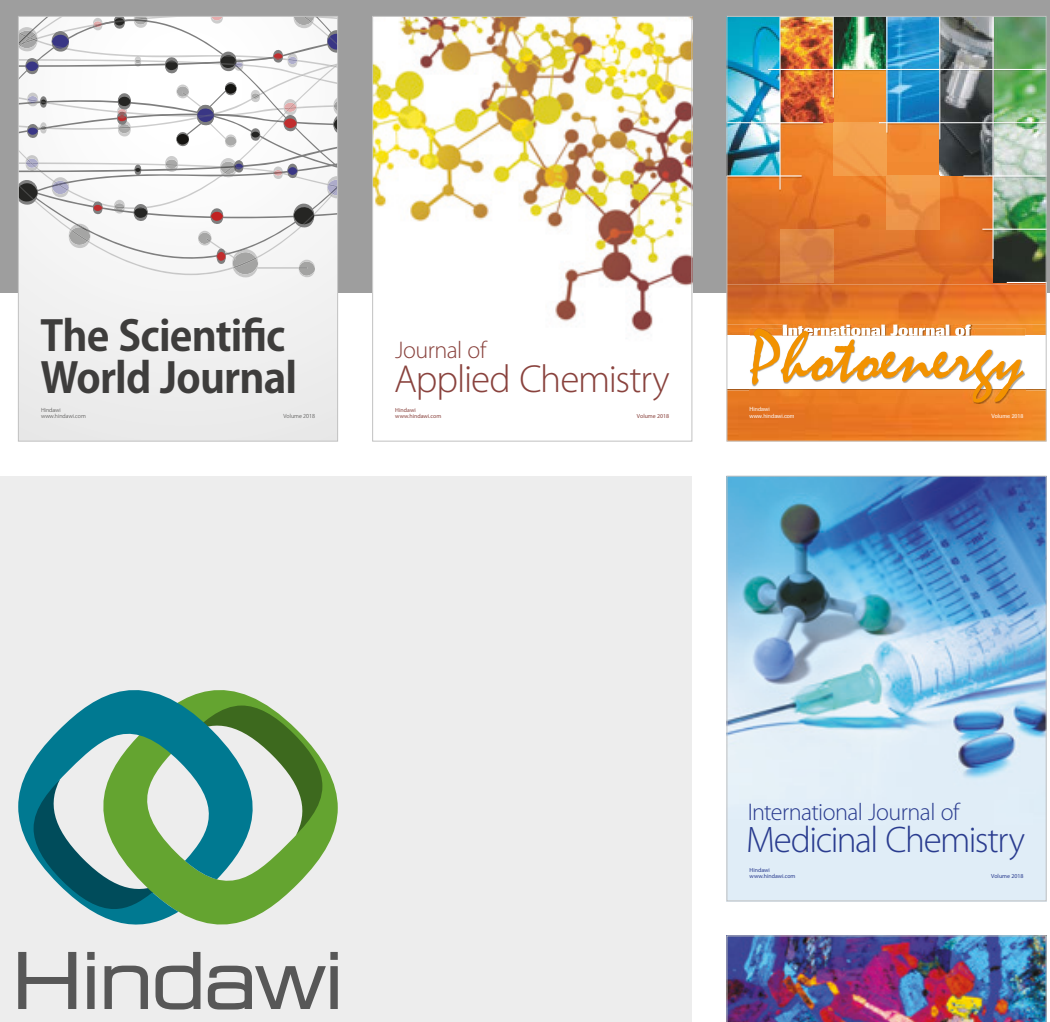

Submit your manuscripts at

www.hindawi.com
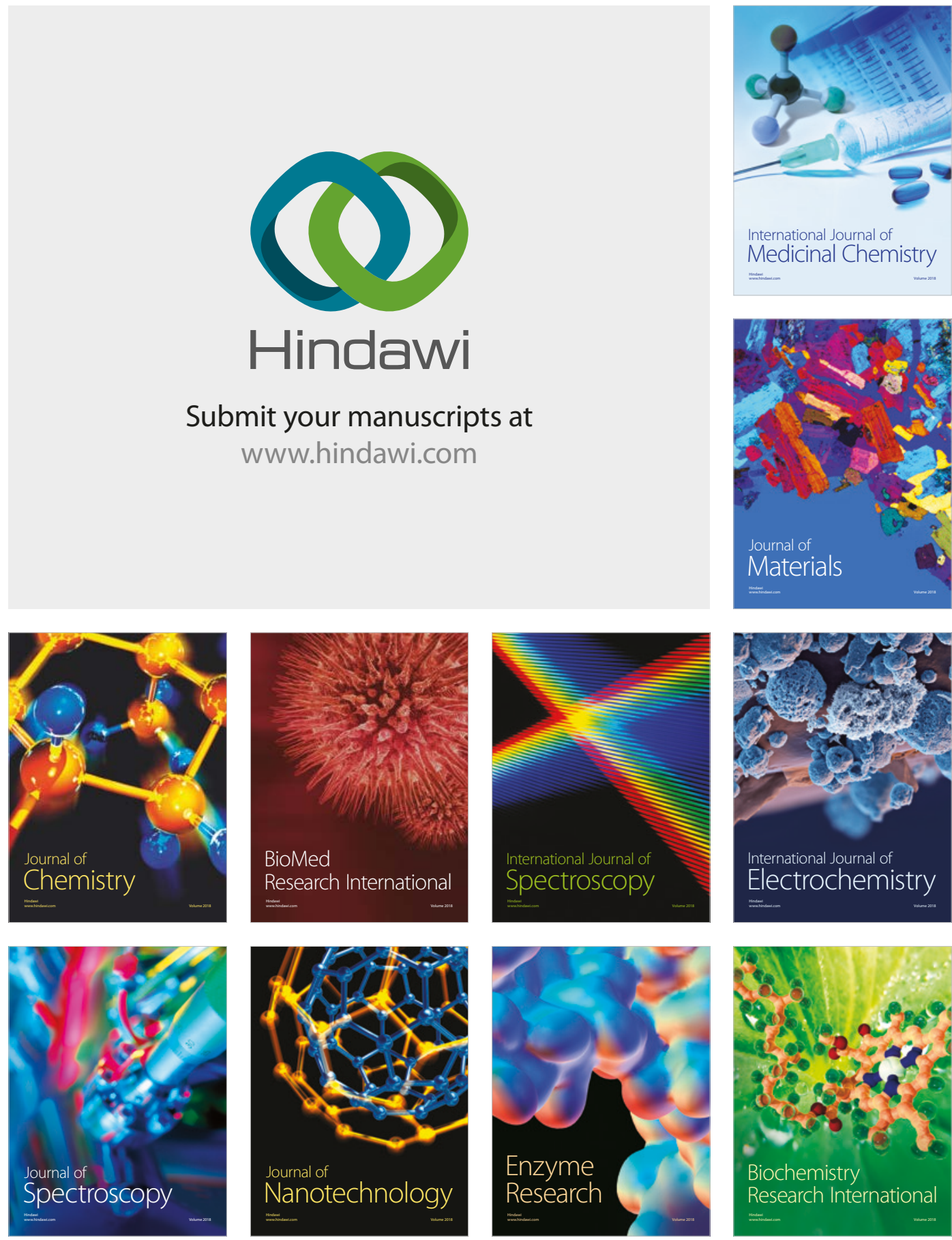
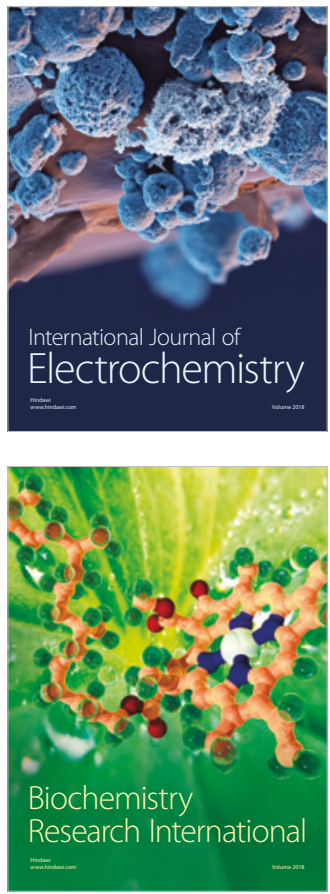